\title{
CORROSION PROTECTION BY CHEMICAL VAPOR DEPOSITION: A REVIEW
}

S. Sathiyanarayanan, G. Rajagopal, N. Palaniswamy and M. Raghavan

Central Electrochemical Research Institute, Karaikudi 630006, India

\begin{abstract}
Material degradation through corrosion is a major threat to any process industry. The losses due to corrosion can be either direct or indirect. Combating this problem by engineering the surfaces is the economically viable solution. Chemical Vapor Deposition is the modern technology whereby the condensation of the solid material takes place from the vapor phase at a higher temperature. CVD finds extensive applications in optical, ceramic, electronic and allied industries. The possibility of controlling the deposition composition, microstructure, and making tailor-made coatings for specific applications has made CVD more user-friendly. This review briefly reviews the thermodynamics, kinetics, design and technological aspects of Chemical Vapor Deposition, and also summarizes its potential use for surface engineering for corrosion and wear protection.
\end{abstract}

\section{INTRODUCTION}

Each metal has its own properties, such as density, melting and boiling points, erosion, wear and corrosion resistance, etc. Specific application of a particular metal imposes special constraints. It will not always be easy to identify a particular material to fulfill all our expectations. Going for a superior material will raise the design cost. Allowing for frequent shut downs for various reasons will affect production and thereby cost. Operating industries face a major threat because of this problem. Such a crucial circumstance can be averted to some extent by modifying the structure with a composite type of coating wherein a few microns of superficial layer will take care of the wear, erosion and corrosion resistance while the cheaper base 
material retains its cost effectiveness. For example, a cutting tool with only a few micron thick coating of Titanium Carbide (TiC) or Titanium Nitride (TiN) over it will show a tremendous improvement in its wear resistance property.

Coatings in general can be achieved by liquid dip coating, electrodeposition, particulate process, physical vapor and chemical vapor deposition. The liquid dip coating method is well known for large scale processing but is inefficient for thin and closely controlled growth. Electrodeposition, in spite of its existence for the past several decades, still faces problems in achieving pore free, thick and uniform coatings over complex shapes. Physical and chemical vapour deposition finds extensive application in modern industrial life.

The chemical vapour deposition process, foremost among modern industrial applications, explores the possibility of depositing almost all the metals available in the periodic table, some of their oxides, ceramic materials, etc., in a precisely controlled manner that finds extensive application in erosion, wear and corrosion resistance coatings, semiconductor industries, optical applications, decorative finishes, etc. /1-7/. Its uniqueness lies in its ability to control and check the quality of the coating at various stages of processing.

\section{THERMODYNAMICS OF CVD}

CVD reactions are complex and several equilibria and interactions have to be taken into consideration. Many data may have to be estimated or even experimentally determined. There are good sources of thermodynamic data 18-10\%. Several computer programmes have also been used in analyzing the complex reactions $/ 11,12 \%$. Ten rules for predicting chemical transport reactions have been formulated by Schafer $/ 13 /$ and the utility of $\mathrm{G}^{\circ}-\mathrm{T}$ diagrams for vapour transport has been attempted by Jeffes et al. /14/. The flow dynamics and modeling of CVD have been discussed 115/. The thermodynamic analysis and deposition of refractory materials have been discussed by Bernard and Madan /16/.

The thermodynamic favourability of a particular CVD reaction is analysed by calculating the transfer of free energy associated with that particular reaction 
The free energy of formation is not a fixed value but varies as a function of several parameters, which include the type of reactants, the molar ratio of these reactants, the process temperature and the process pressure.

The applications of thermodynamics to CVD systems in which the deposition of one particular phase is strongly dominant /17,18/ involve interrelating (a) the controllable experimental variables to (b) the fundamental properties of the system to (c) the chemical compositions and phase assemblages to (d) the deposition rates and efficiencies to (e) the morphological nature and crystallite size of the deposited materials.

The efficient application of thermodynamics to an experimental CVD system needs the clear definition of experimentally controllable variables, the properties of the process that can be calculated and the measurable properties of the system.

Experimentally controllable variables typically include (a) temperature (b) total pressure and (c) the ratios of the chemical elements in the input gas. In addition to these thermodynamic variables, they also include the kinetic variables such as (a) total flow rate (b) system geometry and (c) substrate chemistry. Specific cases have been dealt by many authors /19-22/ by considering the CVD phase diagrams and they were able to optimize the process control of the CVD system by analyzing the efficiency diagrams.

\section{KINETICS OF CVD}

The sequence of events occurring during a CVD reaction can be summarized as follows $/ 23 /$ :

1. The reactant gases enter the reactor by forced flow

2. They diffuse through the boundary layer

3. They are adsorbed on the surface of the substrate where the chemical reaction takes place at the interface. Other events such as lattice incorporation and surface motion may also take place at this stage.

4. The gaseous by-products of the reaction are desorbed and diffuse away from the surface, through the boundary layer.

These sequences occur in order and the slowest one is the rate determining step. This can be determined by either a) the surface reaction kinetics, b) the mass transport, c) gas-phase kinetics. 
In the case of surface reaction kinetics, the quantity of reactant gases available determines the rate occurring at low temperature and low pressure. The diffusion rate of the reactant gases through the boundary layer controls the reaction; it will be mass transport phenomena. i.e. at high pressure and high temperature. Mass transport of a CVD system links diffusion control, chemical kinetics and fluid-flow dynamics. Diffusion growth can be ascertained from chemical kinetics by

\section{Rate constant of growth $=A \exp (-E / k T)$}

where $E$ is the activation energy, $k$ is the Boltzmann's constant and $T$ the temperature. The growth rate changes at a transition temperature from a predominant kinetic to diffusion control with increase in substrate temperature. Hence it is possible in CVD, by controlling the experimental parameters such as temperature and pressure, to switch the process from surface reaction kinetics to mass transport and vice versa. The chemical kinetics and mass transport characterization of chemical vapor deposition are considered with the example of boron trichloride hydrogen reduction. Methods of quickly estimating rates of mass transport are indicated and a mathematical description of the experimentally measured chemical kinetics is given /24/. Several mass transport models have been discussed /25/.

The CVD structure can be either of columnar grains capped by a domelike top or of columnar growths with more facets or made up of fine equiaxed grains.

Designing or specifying the CVD coating reactor for a specific application requires knowledge of a number of factors. It is important to know the type of coatings to be applied, the style and size of the tools to be coated and the uniformity and quality of coating required.

Once the system is specified and designed, it is important that the process instructions are followed to produce the coating quality and production required. The reactant concentration, flow rate, substrate temperature, heating and cooling cycle, coating time and gas purity all have to be adjusted and controlled for specific type of coating.

\section{CVD PROCESS}

In general, the CVD process has the following four stages: 
1. Precursor compound and its vaporization

2. Vapour transport mechanism

3. The reactor and

4. By product disposal system

\subsection{Precursor compound and its vaporisation}

The material to be deposited is taken in some easier form such as halides of metals, etc. The choice of precursor compounds depends on many factors including its volatility, purity, easy availability, vaporization temperature, etc. In some cases, the halides of metals have been formed in situ and used for deposition /26/. A more recent trend is to have a precursor in the form of an organometallic compound with the special features of high volatility and very low vaporizing temperatures $127,28 /$. The precursor compound is heated in a controlled manner to its vaporizing temperature so that the vapour will be available at a constant rate for deposition. An inert gas called the carrier gas will normally be bubbled through the vaporizing column so that the gas will carry away the vapour being generated.

\subsection{Vapour transport mechanism}

Once the vapour is generated from the precursor material, it has to be transported to the CVD reactor for subsequent deposition. This transport is normally achieved through a forced flow by precisely controlling the flow rate of the carrier gas. Normally an inert gas such as hydrogen, argon or nitrogen is used as carrier gas. The vapour transporting path is also heated and precisely monitored and controlled, normally to a temperature which is slightly less or equal to that of vaporizing temperature so as to prevent the vapour from condensing along the path. A mass transport monitor-cumcontroller can also be included in this section to evaluate the efficacy of the CVD system.

\subsection{The reactor}

In the CVD reactor, the substrate is kept at a temperature that is sufficiently high that the transported precursor vapor will decompose and form the required coating. Depending upon the requirement, the reactor may 
operate at ultra high vacuum (Vacuum CVD) or at atmospheric pressure (APCVD). Heating of the substrate can either be achieved through conventional resistive heating (for bulk processing) or through inductive heating. In resistive heating (hot wall reactors), the deposition will occur all over the walls of the reactor. To enhance uniformity, a complex motion such as rotation or oscillation will be given to the substrate. The main drawback of the CVD is its high temperature requirement of the substrate which most commercial metals do not withstand. This problem could be solved by introducing plasma into the reactor, thereby substantially reducing the substrate temperature. This process is called Plasma Assisted CVD 129-35/. Use of metallo-organic precursor compounds (MOCVD) also helps in decreasing the substrate temperature $/ 17 /$. Local in situ heating of narrow regions of substrate by pointed Laser beams also facilitates the writing of metals by CVD /36,37/. Modeling of CVD reactors has been discussed /38/ and a number of CVD reactor models have appeared in recent literature. Three dimensional effects in horizontal reactors for $\mathrm{Si}$ from $\mathrm{SiH}_{4}$ /39/, a mathematical model for CVD of boron $/ 40 /$, a hot wall reactor for close spaced vapour transport deposition systems $/ 41 /$, models to meet needs of VLSI and MOCVD /42/, vertical flow reactor model /43/, a versatile reactor for UHV applications based on reusable metal sealing system $/ 44 /$, and a fluid mechanical model for CVD in a horizontal R.F. reactor $/ 45 /$ are just a few of many.

\subsection{By product disposal system}

Many CVD processes use precursors that are toxic and in some cases lethal even at lowest concentrations. Many precursors are also pyrophoric, such as silane, some alkyls, arsine and phosphine. Very often the reaction is not complete and some of the precursor materials may reach the exhaust unreacted. In addition, many of the by-products of the reaction are also toxic and corrosive. For example, deposition of $\mathrm{TiC}$ from $\mathrm{TiCl}_{4}$ and methane gas will yield $\mathrm{HCl}$ gas as by product. This suggests that all the effluents must be eliminated or neutralized before they are released to the environment.

\subsection{CVD Reactions}

There exist several categories of CVD reactions, some representatives of which are described below: 
1. Thermal decomposition or pyrolysis

Because of high temperature gradient, a molecule is broken apart into its elements

Ex. $\mathrm{CH}_{3} \mathrm{SiCl}_{3}(\mathrm{~g}) \longrightarrow \mathrm{SiC}(\mathrm{s})+3 \mathrm{HCl}(\mathrm{g})$

2. Hydrogen reduction

Ex. $\mathrm{SiCl}_{4}(\mathrm{~g})+2 \mathrm{H}_{2}(\mathrm{~g}) \longrightarrow \mathrm{Si}(\mathrm{s})+4 \mathrm{HCl}$

This type of hydrogen reduction generally takes place at a lower temperature than the equivalent decomposition reaction. Another supplementary role is that the hydrogen used in these reactions prevents the formation of oxides.

3. Metal reduction of halides

Powerful reductants such as zinc, cadmium, magnesium, sodium and potassium are used for reduction as

Ex. $\mathrm{TiCl}_{4}(\mathrm{~g})+2 \mathrm{Mg}(\mathrm{s}) \longrightarrow \mathrm{Ti}(\mathrm{s})+2 \mathrm{MgCl}_{2}(\mathrm{~g})$

4. Oxidation and hydroloysis reactions

Ex. $\mathrm{SiH}_{4}(\mathrm{~g})+\mathrm{O}_{2}(\mathrm{~g}) \longrightarrow \mathrm{SiO}_{2}(\mathrm{~s})+2 \mathrm{H}_{2}(\mathrm{~g})$

5. Reactions to form carbides and nitrides

Carburisation is usually achieved by reacting a halide with a hydrocarbon such as methane

Ex. $\mathrm{TiCl}_{4}(\mathrm{~g})+\mathrm{CH}_{4}(\mathrm{~g}) \longrightarrow \mathrm{TiC}(\mathrm{s})+4 \mathrm{HCl}(\mathrm{g})$

\section{APPLICATIONS OF CVD ENGINEERED SURFACES}

A more recent review of CVD coatings - from cutting tools to aerospace applications - by Pocket et al. /46/ highlighted the uniqueness of CVD because of its versatility and its ability to provide an inexpensive means of molecular forming. This review also explores the historical development of protective coatings and attempts to predict their future direction in the cutting tool and aerospace fields. The properties of coatings such as structure, porosity, density, stress, corrosion, hydrogen permeation, tribology, fatigue and thermal contact conductance produced by CVD and other methods were compared $/ 47 /$. A mathematical model to predict the deposits obtained by Laser CVD for the deposition of thin film of oxidation, corrosion and wear resistant materials as well as electronic, opto-electronic and super conductor materials has been discussed /48/. 


\subsection{General Corrosion}

Corrosion is defined as the wearing of a surface by chemical action. Virtually all the metals can be deposited over any metallic substrate. One can easily identify a more noble metal from the electrochemical series and have a deposition. The main problem posed by CVD is that the thermal expansion coefficient of the substrate metal and the coating metal should agree. In addition, the substrate should withstand the required deposition temperature. A corrosion resistant titanium rich deposit prepared by CVD at low temperature $\left(<600^{\circ} \mathrm{C}\right)$ from Tris-(2.2'-bispyridine)titanium compound has been discussed by Morancho et al. $149 \%$.

\subsubsection{CVD Borides for Corrosion Applications}

Typical borides are $\mathrm{HfB}_{2}, \mathrm{Mo}_{2} \mathrm{~B}_{5}, \mathrm{NbB}_{2}, \mathrm{TaB}_{2}, \mathrm{TiB}_{2}, \mathrm{~W}_{2} \mathrm{~B}_{5}, \mathrm{ZrB}_{2}$. Borides are relatively inert, especially to non-oxidizing reagents. They react violently with fluorine. Resistance of these borides to acids and alkalis is summarized 14/. Borides are generally resistant to molten metals, at least to those that do not readily form borides.

\subsubsection{CVD Carbides for Corrosion Applications}

$\mathrm{TiC}$ has good resistance to sulfuric acid /50/. Deposition parameters controlling CVD of TiC on steel have been discussed by Derre et al. $151 /$. A passivating oxide layer is formed up to a potential of $1.8 \mathrm{~V}$ at which point the corrosion becomes very severe. $\mathrm{TiC}$ is also very resistant to sea water, neutral industrial waste waters and human sweat. TiC coatings by CVD are also presented $/ 52 / . \mathrm{Cr}_{7} \mathrm{C}_{3}$ is even more corrosion resistant and is used widely as a passivating layer. Carbides oxidize rapidly and they are also not resistant to molten slags and fused salts. Coherent layers of $\mathrm{W}_{2} \mathrm{C}$ with thickness up to $100 \mu \mathrm{m}$ and hardness of about 2300 V.P.N can be obtained by the reaction of tungsten hexa fluoride hydrogen and an aromatic hydro carbon in the temperature range $400-700^{\circ} \mathrm{C} / 53 /$.

\subsubsection{CVD Nitrides for Corrosion Applications}

TiN, ZrN and $\mathrm{HfN}$ have high thermal and chemical stability. In comparison, the chemical stability is less for $\mathrm{VN}, \mathrm{NbN}$ and $\mathrm{TaN}$ and is very much less for $\mathrm{CrN}$ and MoN and WN. CVD TiN, ZrN and HfN are the most commonly used. They provide a good barrier to diffusion and their resistance 
to acids is generally good. $\mathrm{BN}$ is one of the most outstanding corrosion resistant materials. TiN is extremely resistant to sea water and human sweat.

\subsubsection{CVD Oxides for Corrosion Applications}

The refractory oxides such as alumina, hafnia, silica, titania and zirconia have characteristic excellent oxidation resistance. The chemical resistance of CVD oxides in reducing atmospheres, carbon, acid and basic slags and molten metals is summarized by Campbell and Sherwood 154\%. The conditions for obtaining $\mathrm{TiO}_{2}$ over surgical stainless steel type $316 \mathrm{~L}$ by plasma assisted CVD have been attempted /55/. This coating increases the pitting and general corrosion resistance of steel. Any damage or partial removal of the coating does not cause an increased galvanic corrosion of the substrate.

\subsection{Oxidation Resistant Coatings}

For oxidation resistant surfaces, chromizing, aluminizing and siliconizing have been widely used. Siliconizing is extremely good for refractory metals and alloys since $\mathrm{MoSi}_{2}, \mathrm{WSi}_{2}$ and $\mathrm{VSi}_{2}$ have good oxidation resistance. CVD coatings of $\mathrm{SiO}_{2}$ are used to protect $9 \%$ chrome steels from oxidation in high pressure $\mathrm{CO}_{2}$ Advanced Gas Cooled Reactors /56,57/ but thermal shock cracks can occur. A CVD $\mathrm{SiO}_{2}$ coating on both clean and corroded steel greatly reduced the oxidation rate $136 / . \mathrm{SiO}_{2}$ on $20 \mathrm{Cr} 25 \mathrm{NiNb}$ stainless steel reduced the oxidation rate by 5 times in $\mathrm{CO}_{2}$ at $825^{\circ} \mathrm{C} / 58 / . \mathrm{CVD}$ coatings of $\mathrm{ZrC}_{\mathrm{x}} \mathrm{N}_{\mathrm{y}}$ are used for solar energy absorption, wear resistance for carbide cutting tools and refractory protective coatings for nuclear fuel elements $159 \%$ $\mathrm{Si}_{3} \mathrm{~N}_{4}$ CVD coatings are used on Mo /60/. CVD of $\mathrm{Si}_{3} \mathrm{~N}_{4}$ to metal substrates at reduced pressure was carried out by the reaction of $\mathrm{SiCl}_{4}, \mathrm{NH}_{3}$ and $\mathrm{H}_{2}$ gases at $1373 \mathrm{~K} / 61 /$. TiN was deposited prior to the $\mathrm{Si}_{3} \mathrm{~N}_{4}$ coating on an intermediate layer in order to avoid the formation of metal silicide. By keying effect the needle shape morphology of TiN increased the adhesion between TiN and $\mathrm{Si}_{3} \mathrm{~N}_{4}$. The oxidation resistance of the film was evaluated by a cyclic heating test in air at $1073 \mathrm{~K}$ with samples being dipped in $\mathrm{NaCl}$ saturated solution for every 50 cycles. The film showed very good oxidation resistance compared with heat resistant alloys in the corrosive environment. $\mathrm{TiB}_{2} \mathrm{CVD}$ coatings are very resistant to chemical and oxidation attack $/ 10 / . \mathrm{Ti}_{5} \mathrm{Si}_{3} \mathrm{CVD}$ coating on titanium greatly reduces the oxidation rate but cracks occur after long periods /62\%. Life time extension of valve seals and stems used in 
nuclear power plants was achieved by a unique ceramic coating using plasma CVD /63/. Multi-layer coatings of $\mathrm{Al}_{2} \mathrm{O}_{3} / \mathrm{TiN} / \mathrm{TiC}, \mathrm{Al}_{2} \mathrm{O}_{3} / \mathrm{TiC}$ and TiN/TiC were deposited onto stellite and stainless steel. The mechanical and physical properties of the coatings were evaluated by various methods. The coated specimens showed good wear resistance in high temperature water environment.

The high temperature oxidation of CVD SiC has been studied by Goto et al. 164/. The deposition was found to increase with increasing the oxygen partial pressure in $\mathrm{Ar}-\mathrm{O}_{2}$ atmosphere. The corrosion behaviour of $\mathrm{SiC}$ and $\mathrm{Si}_{3} \mathrm{~N}_{4}$ prepared by CVD in molten $\mathrm{Na}_{2} \mathrm{SO}_{4}$ was studied $/ 65,66 /$ and was reported as the corrosion of both the materials in argon - oxygen mixture was less severe compared to that in $\mathrm{Ar}$; the reason for this is the formation of $\mathrm{SiO}_{2}$ which acts as a protective film against corrosion.

A high temperature corrosion kinetic study of HK40 super alloy surface treated using silicon nitride in contact with eutectic mixture of $82 \% \mathrm{~K}_{2} \mathrm{~S}_{2} \mathrm{O}_{7}$ $18 \% \mathrm{~V}_{2} \mathrm{O}_{5}$ has been attempted $/ 67 /$.

\subsection{Hard Overlay Coatings}

Wear resistance is an important feature of surface coatings which the industry often needs. Coatings of TiC, TiN and $\mathrm{Ti}(\mathrm{C}, \mathrm{N})$ are used on tools. $\mathrm{TiC}$ on punching dies, thread guides, cemented carbide tool inserts, on steel ball bearings for use in severe conditions and on pistons and valves /68/. $\mathrm{Ti}(\mathrm{C}, \mathrm{N})$ is deposited on carbon steel nail heads to improve adherence and toughness 169 . High micro hardness $\mathrm{TiC}$ coatings from propane gives columnar structure in $\langle 200\rangle$ growth direction $/ 70 \% . \mathrm{TiB}_{2}$ deposited on $\mathrm{Fe}$ gives adherent thick film $/ 71 /$. TiN deposition on cemented carbides using conventional CVD process and its performance related to this technology has been extensively reviewed $/ 72,73$. Most of the publications regarding TiN deposition on different substrates were concerned with thermodynamics /74,75/ and the kinetic aspects of the coating process /76/. A study to determine the relationship between the linear flow velocity of the gas mixture and some of the coating properties and morphological characteristics has also been conducted. TiN is also the most investigated wear resistant refractory in recent years with a wickers hardness of $1600-2000$. It also improves the adherence and toughness. In a mobile furnace TiN was coated inside long steel tubes of $10 \mathrm{~mm}$ ID at $1050^{\circ} \mathrm{C} / 77 /$. More homogenous coatings are obtained with the furnace moving along the outlet to inlet direction. The 
CVD of TiN on stainless steel was attempted by Staia et al. 178/; thin, inhomogenous coatings were seen at low linear velocities, whereas better properties appeared at high velocities. $\mathrm{TiN}, \mathrm{Ti}(\mathrm{B}, \mathrm{N})$ and $\mathrm{TiC}$ and the multilayers of the system Ti-C-N were deposited in order to analyze their application in aluminium die casting with regard to economical and ecological aspects. The coatings reached hardness values up to $4400 \mathrm{KH}$ and the friction coefficient was in the range of 0.3 . Cross sectional grain morphology of CVD TiC by TEM /79/ has shown that these coatings have two distinct zones, namely a sub-micron zone where the growth rate of the $\mathrm{TiC}$ is controlled by diffusion of $\mathrm{C}$ from substrate, and a coarse columnar or equiaxed zone, which is dependent on the activity in the reactor. The CVD of $\mathrm{SiC}$ and silicon nitride on tools for electrochemical machining has been discussed $/ 80 \%$.

A parametric study of the micro-structural, mechanical and tribological properties of PACVD TiN was carried out by Mogensen et al. /81/ who found that the residual stress level and hardness varied significantly with changes in process parameters; the tribological properties displayed only minor variations.

Erosion resistant $\mathrm{TiB}_{2}$ on valve and pump components was reported at $750-1050^{\circ}$ using chlorides of $\mathrm{Ti}$ and $\mathrm{B}$ with $\mathrm{H}_{2}$ as carrier gas and reducing gas $/ 82,83 /$. A study was made of the corrosion properties of titanium based hard coatings such as $\mathrm{TiN}$, titanium boronitride $\mathrm{Ti}(\mathrm{B}, \mathrm{N})$ and titanium carbonitride $\mathrm{Ti}(\mathrm{C}, \mathrm{N})$ coatings which were deposited by plasma assisted CVD /84/ on tempering and SS substrates. The coatings were characterized by XRD, SEM, impedance and cyclic voltammetric studies. The potential of hard coatings for wear protection in plastic processing units was investigated by Heinze $185 /$. Erosion resistant tungsten coatings for rocket nozzle applications has been discussed by Sherwood et al. /86/. Very hard CVD SiC layers grown on WC-Co based cemented carbide $/ 87 /$ show a fine grain structure and poor adhesion properties, attributed to the presence of detrimental $\mathrm{CoSi}$ interlayer. Intermediate multilayers of CVD TiN, $\mathrm{Ti}(\mathrm{C}, \mathrm{N})$, $\mathrm{TiC}$ acted as diffusion barrier to cobalt.

Plasma enhanced MOCVD of wear resistant $\mathrm{Ti}(\mathrm{C}, \mathrm{N})$ layers on tool steel for the metal organic compounds like $\mathrm{Ti}\left(\mathrm{N} \mathrm{Me}_{2}\right)$ (4), $\mathrm{Ti}\left(\mathrm{NEt}_{2}\right)$ (4) and t-Bu Ti $\left(\mathrm{NMe}_{2}\right)$ (3) in combination with $\mathrm{N}_{2}, \mathrm{H}_{2}$ and $\mathrm{Ar}$ in reactor were reported by Driessen et al. $/ 88 /$.

The advances of PACVD and the development of low temperature PACVD and industrial applications of these techniques for the development 
of wear and corrosion resistant surface systems have been suggested /89/. Multilayer coatings in the Ti-N were suggested by Bull and Jones $190 /$, showing the advantages of compositionally and structurally modulated coatings over conventional single layer TiN coatings in tribological applications. The results were discussed in light of the microstructure and properties of the coatings produced by the two different multiplayer coating techniques.

Erosion resistant coatings are also needed for leading edges of gas turbine blades and aluminide coatings achieved by pack cementation are used for this purpose. $\mathrm{CVD} \mathrm{Cr}_{7} \mathrm{C}_{3}$ replaces $\mathrm{Ti}(\mathrm{C}, \mathrm{N})$ with much better thermal and mechanical shock resistance and erosion resistance.

\section{REFERENCES}

1. C.F. Powell, I.E. Campbell and B.W. Gonser, Vapor Plating, Electrochemical Society, John Wiley \& Sons Inc., N.Y., 1955.

2. J.M. Blocher, Jr., CVD in Deposition Technologies for Films and Coatings, R.F. Bunshah et al. (Eds.), Noyes, N.J., U.S.A., 1982; p. 335.

3. J.O. Carlsson, CVD in Deposition Technologies for Films and Coatings, R.F. Bunshah et al. (Eds.), Noyes, N.J., U.S.A., 1994; p. 374.

4. H.O. Pierson, Handbook of CVD, Noyes, N.J., U.S.A., 1992.

5. M.G. Hocking, V. Vasantrasree and P.S. Sidky, Metallic and Ceramic Coatings, Longman Scientific \& Technical/John Wiley \& Sons Inc., N.Y., 1989.

6. T.T. Kodas and M.J. Hampden-Smith, The Chemistry of Metal, CVD, VCH, N.Y., 1994.

7. A. Kempster, Trans. IMP, 76 (6), B88 (1998).

8. C. Bernard, Proc. 8th Intl. Conf., J.M. Blocher and G.E. Vuillard (Eds.), $1981 ;$ p. 3.

9. R. Colmet et al., Proc. 8th Intl. Conf., J.M. Blocher and G.E. Vuillard (Eds.), 1981; p. 17.

10. L. Vandenbulcke, Proc. 8th Intl. Conf., J.M. Blocher and G.E. Vuillard (Eds.), $1981 ;$ p. 32.

11. T.M. Besmann and K.E. Spear, J. Electrochem. Soc., 124 (5), 790 (1977).

12. L. Hunt and E. Sirtl, J. Electrochem. Soc., 119, 1771 (1972). 
13. H. Schafer, Chemical Transport Reactions, Academic Press, N.Y., 1964.

14. J.H.E. Jeffes, J. Cryst. Growth, 3, 13 (1968).

15. F. Rosenberger, Proc. 10th International Conference on CVD, Pennington, N.J., 1987; p. 11.

16. C. Bernard and R. Madan, Surf. Coat. \& Technol., 49, 208 (1991).

17. M.E. Jones and D.E. Shaw, "Growth from the vapour", in: Treatise on Solid State Chemistry, Vol. 5, Plenum Press, N.Y., 1975.

18. M.M. Faktor and I. Garrett, Growth of Crystals from the Vapour, Chapman \& Hall, London, 1974.

19. T.M. Besmann and K.E. Spear, J. Electrochem. Soc., 124, 786 (1977).

20. C.F. Wan and K.E. Spear, Proc. 6th Intl. Conf. on CVD, Electrochem. Soc., Princeton, N.J., 1977; p. 47.

21. M. Ducarroir and C. Bernard, Proc. 5th Intl. Conf. on CVD, Electrochem. Soc., Princeton, N.J., 1975; p. 72.

22. M. Ducarroir and C. Bernard, J. Electrochem. Soc., 123, 136 (1976).

23. K.E. Spear, Thermodynamical modeling of steady state CVD process, in: Proc. 9th Intl. Conf. on CVD, Electrochem. Soc., Princeton, N.J., 1984; p. 81.

24. P.E. Gruber, Proc. 2nd Intl. Conf. on CVD, J.M. Blocher Jr. and J.C. Withers (Eds.), 1970; p. 25.

25. J.M. Blocher, in: Chemical Vapour Deposition, B.E. Jacobson and R.F. Bunshah (Eds.), Sweden, 1982.

26. B.C. Smoak Jr. and D. O'Ferrel, Semiconductor International, 1990; p. 88.

27. J.L. Zilko, Metallo-organic CVD technology and equipment, in: Handbook of Thin-Film Deposition Process and Techniques, K.K. Shuegraf (Ed.), Noyes Publications, 1988.

28. K. Nakamura, J. Electrochem. Soc., 133 (6), 1120 (1986).

29. J.R. Hollahan and R.S. Rosler, Plasma deposition of inorganic thin films, in: Thin Film Processes, J. Vossen and W. Kern (Eds.), Academic Press, N.Y., 1978.

30. P.K. Bachman, G. Gartner and H. Lydtin, Plasma assisted CVD processes, MRS Bulletin, 51-59 (1988).

31. D. Kuppers, Proc. 7th Intl. Conf. on CVD, Electrochem. Soc., Princeton, N.J., 1979.

32. T.D. Bonifield, in: Deposition Technologies for Films and Coatings, R.F. Bunshah (Ed.), Noyes, N.J., 1982; p. 365. 
33. A.R. Reinberg, Ann. Rev. Mat. Sci., 9, 341 (1979).

34. M.S. Rand, J. Vac. Sci. \& Technol., 16, 420 (1979).

35. A. Sherman, Plasma enhanced CVD, in: Handbook of Deposition Technologies for Films and Coatings, R.F. Bunshah (Ed.), 2nd Ed., Noyes, N.J., 1994; p. 434.

36. D. Bauerle, Laser induced CVD, in: Laser Processing and Diagnostics, D. Bauerle (Ed.), Springer-Verlag, New York, 1984.

37. F. Shaapur and S.D. Allen, Surf. \& Coat. Technol., 33, 491 (1987).

38. K.F. Jensen, Proc. 9th Intl. Conf. on CVD, Pennington, 1984; p. 3.

39. H.K. Moffat and K.F. Jensen, J. Electrochem. Soc., 135, 459 (1988).

40. H. Rebenne and R. Pollard, J. Electrochem. Soc., 132, 1932 (1985).

41. C. Menezes, C. Fortmann and S. Casey, J. Electrochem. Soc., 132 (3), 709 (1985).

42. C. Houtman, D.B. Graves and K.F. Jensen, J. Electrochem. Soc., 133 (5), 961 (1986).

43. M.E. Coltrin, R.J. Kee and J.A. Miller, J. Electrochem. Soc., 133 (6), 1206 (1986).

44. T.R. Hayes, J.F. Evans and T.W. Rusch, J. Vac. Sci. \& Technol., A3 (4), 1768 (1985).

45. C.L. Remiller, Proc. 9th Intl. Conf. on CVD, Pennington, 1984; p. 21.

46. L.F. Pocket, P. Howard and S. Safaie, Surf. Coat.Technol., 94-5 (1-3), 70 (1997).

47. J.W. Dini, Mater. Manuf. Process, 12 (3), 437 (1997).

48. A. Kar and J. Mazumder, Mater. Sci. Eng. Bu. Solid State M., 41 (3), 368 (1996).

49. R. Morancho, J.A. Petit, F. Dabosi and G. Constent, Proc. 7th Intl. Conf. on CVD, Princeton, N.J., 1979; p. 593.

50. H. Hintermann, Engineering Ceramics, Sterling Publications, London, 1988; pp. 54-59.

51. A. Derre, M. Ducarroir and F. Teyssandig, Proc. 10th Intl. Conf. on CVD, Pennington, N.J., 1987; p. 1190.

52. W. Ruppert, Proc. 2nd Intl. Conf. on CVD, 1970, p. 443.

53. N.J. Archer, Proc. 5th Intl. Conf. on CVD, 1975; p. 556.

54. I. Campbell and E. Sherwood, High Temperature Materials \& Technologies, John Wiley \& Sons, N.Y., 1967.

55. J. Gluszek, J. Masalski, P. Furman and K. Nitsch, Biomaterials, 18 (11), 789 (1997). 
56. A.M. Brown, J. Graham, K.G. Sannders and P.L. Surman, Corr. Sci., 18, 337 (1978).

57. J. Graham, High Temp. \& High Pressure, 6, 577 (1974).

58. M.J. Bernet, M.R. Houlton and R.W.M. Hawes, Corr. Sci., 22 (2), 111 (1982).

59. S. Zirinsky and E.A. Irene, J. Electrochem. Soc., 124 (2), 305 (1978).

60. F.S. Galasso, R.D. Veltri and W.J. Cros, Am. Ceram. Soc. Bull., 57 (4), 453 (1978).

61. T. Taniuchi, T. Adachi and K. Kobayashi, Surf. Coat. Tech., 49, 13 (1998).

62. A. Abba, A. Galerie and M. Caillet, Oxid. Met., 17 (1), 43 (1982).

63. T. Yoshioka, H. Ukegawa, H. Kerwai, N. Fukita and T. Igarashi, Surf. Coat. Tech., 49, 97 (1991).

64. T. Goto, H. Homma, T. Hirai, T. Narushima and Y. lguchi, High Temp. Cor. An., 98 (9), 395 (1998).

65. D.Y. Song, S. Kitalka and H. Kawamoto, J. Mater. Sci., 33 (4), 1031 (1998).

66. T. Nakagawa, M. Hara and K. Imai, J. Jpn. Inst. Metal, 61 (11), 1241 (1997).

67. E. Otero, A. Pardo, F.J. Perez, J.F. Alwarez and M.V. Utrilla, Corros. Sci., 39 (1), 133 (1997).

68. H. Gass and H.E. Hintlemann, Proc. 4th Intl. Conf. on CVD, G.F. Wakefield and 1.M. Blocher (Eds.), Electrochem. Soc., Princeton, N.J., 1974.

69. T. Takahashi and H. Itoh, J. Mat. Sci., 14 (6), 1285 (1979).

70. Dong Soo Baik, Moo Sling Kim and S. John, 9th Intl. Conf. on CVD, Pennington, 1984; p. 745.

71. T. Takahashi and H. Itoh, J. Electrochem. Soc., 124 (5), 797 (1977).

72. H.F. Rebenne and D.G. Bhat, Surf. Coat. Tech., 63, 1 (1994).

73. M.E. Sjostrand, Proc. 7th Intl. Conf. on CVD, Princeton, N.J., 1979; p. 452.

74. F. Leyssandien, C. Bernard and M. Ducanoir, J. Mater. Sci., 23, 135 (1988).

75. D.G. Bhat, Proc. 11th Intl. Conf. on CVD, K.E. Spear and G.W. Gullen (Eds.), Electrochem. Soc., Pennington, N.J., 1990; p. 618.

76. N. Nakanichi, S. Mori and F. Kato, J. Electrochem. Soc., 137, 122 (1990).

77. H. Itoh, K. Kato and K. Sugiyama, J. Mater. Sci., 21, 751 (1986). 
78. M.H. Staia, B. Lewis, J. Cawlay and T. Hudson, Surf. Coat. Tech., 7677, 231 (1995).

79. V.K. Sarin, Proc. 7th Intl. Conf. on CVD, Princeton, N.J., 1979; p. 476.

80. G. Verspui, Proc. 7th Intl. Conf. on CVD, Princeton, N.J., 1979; p. 463.

81. K.S. Mogensen, N.B. Thomsen, S.S. Eskildsen, C. Mathiasen and J. Bottiger, Surf. Coat. Tech., 99 (12), 140 (1998).

82. A. Caputo, W.J. Lackey, I.G. Wright and P. Angelini, J. Electrochem. Soc., 132 (9), 2274 (1985).

83. A. Caputo, W.J. Lackey and I.G. Wright, Proc. 9th Intl. Conf. on CVD, 1984; p. 872.

84. M.K. Hirschfeld, C. Pfohl, K.T. Rie and J.W. Schultze, Materialwiss. Werkstofftech., 29 (9), 484 (1998).

85. M. Heinze, Surf. Coat. Tech., 105 (1-2), 38 (1998).

86. P.J. Sherwood, C. Hayman and A. Bowny, Proc. 5th Intl. Conf. on CVD, 1975; p. 801.

87. G. Giunta, M. Fiorini, V. Vittori and G. Marchesano, Surf. Coat. Tech., 49, 174 (1991).

88. J.P.A.M. Driessen, A.D. Kupers and J. Schoonman, Proceedings of EUROMAT 97, 1997; p. 13.

89. H. Ahn, C. Pfohl, J. Whole, A. Gebauer, S. Bierner, A. Bulak, E. Menthe, E.R. Cabeo and T. Stucky, Materialwiss. Werkstofftech., 27 (12), 57 (1996).

90. S.J. Bull and A.M. Jones, Surf. Coat. Tech., 78 (1-3), 173 (1996). 